\title{
Characterization of an Axial-Injection Plasma Spray Torch
}

\author{
Stephan Zimmermann ${ }^{1} \cdot$ Georg Mauer $^{2}$ (1) $\cdot$ Karl-Heinz Rauwald ${ }^{2} \cdot$ \\ Jochen Schein ${ }^{1}$
}

Submitted: 4 April 2021/in revised form: 21 May 2021 / Accepted: 15 June 2021/Published online: 22 July 2021

(C) The Author(s) 2021

\begin{abstract}
The Axial III ${ }^{\mathrm{TM}}$ torch is a multiple-arc plasma generator with a set of three single cathode-anode units, which is still of significant importance, especially in the field of suspension plasma spraying. The division of the plasma generator into three spatially separated systems allows for central feedstock injection with improved deposition rates and efficiencies. In this work, several diagnostic methods were applied to characterize the plasma jet of an Axial III ${ }^{\mathrm{TM}}$ spray torch to further the understanding of this spray system. One important result was that the plasma temperature in the jet exhibits a triple distribution with three straight lobes arranged around the jet axis. As with every plasma torch, the total plasma power is subject to fast temporal variations. Power variations were clearly seen in the plasma jet even though it could have been anticipated that the triple jet characteristics and the natural fluctuations of the arcs generated by the three single cathode-anode units would be less pronounced after merging the three plasma streams. Unaffected by this it is nevertheless likely that the axially injected feedstock particles are caged effectively in the core of the plasma jet. Hence, the total electrical torch power and the uniformity of the single unit's powers must be monitored to realize possible degradation and asymmetries in the plasma temperature distribution, which may influence deposition parameters.
\end{abstract}

Georg Mauer

g.mauer@fz-juelich.de

1 University of Federal Armed Forces Munich IPM (LPT), Neubiberg, Germany

2 Forschungszentrum Jülich GmbH, IEK-1, Jülich, Germany
Keywords axial injection $\cdot$ high-speed camera $\cdot$ multiplearc torch · plasma spraying $\cdot$ tomography

\section{Introduction}

In the past, several concepts for multiple-arc plasma generators were proposed for thermal spraying (Ref 1-4). They can be distinguished by the relative position of the arcs. One motivation of these developments was to achieve a stable plasma jet with less fluctuations than obtained by a single-cathode torch. Also, the long-term stability and lifetime could benefit from the lower maximum power density as the plasma energy is divided on several arcs which, depending on the respective torch concept, can be controlled individually. Moreover, the division of the entire plasma generator into three spatially separated systems opens up the possibility of central feedstock injection for thermal spraying. Radial injection in traditional DC plasma torches induces variations in particle treatment as larger ones tend to pass through the plasma, while smaller ones tend to bounce off (Ref 5). However, this effect is minimized with axial injection torches in which the feedstock is injected in the center of the plasma stream and thus does not have to pass through the more turbulent outer fringes of the plasma. Extensive melting of the injected powders and thus high deposition rates and deposition efficiencies can be expected (Ref 6). However, axial feedstock injection also increases the complexity of the plasma torch and limits the size of suspension feeding lines, since the lines have to pass between the torch electrodes (Ref 7). Examples for multiple-arc plasma generator systems with merging and separate arcs, respectively, are given in Fig. 1.

The Axial III ${ }^{\mathrm{TM}}$ series 600 plasma torch (Northwest Mettech Corp., Surrey, BC, Canada) is a spray device with 
a set of three single cathode-anode units and thus features three separate arcs. It is based on the patent granted 1996 to Ross and Burgess (Ref 8). The three plasma jets generated by three independent direct current (DC) arcs converge and form one unified plasma jet inside the torch (Ref 9). Thus, this torch consists essentially of three plasma generators, each with single cathode and anode. It can be equipped with nozzles of three different diameters and is operated up to a total input power of $150 \mathrm{~kW}$.

In the last years, the Axial $\mathrm{III}^{\mathrm{TM}}$ was often applied for suspension plasma spraying (SPS) (Ref 10-12). Lee et al. investigated the splats sprayed by an Axial III $^{\mathrm{TM}}$ plasma torch. The fragmentation of the suspension droplets due to the interaction of axially fed suspension with the thermal plasma jet was assumed to be severe as the volume of the deposited splats corresponded almost to that of the individual solid feedstock particles, regardless of the primary droplet size and the solid content of the suspension (Ref 13). Tarasi et al. measured the in-flight characteristics (velocities and temperatures) of powder particles sprayed with the Axial III torch and correlated the results with coating properties (Ref 14, 15). In SPS, however, the small size of the particles prevents individual in-flight particle detection, so that an ensemble particle diagnostic system, which senses the fluctuations of the total emitted radiation in the field of view, is deemed necessary (Ref 16, 17). By axial injection, high impact velocities on the substrate can be achieved. Hence, Stokes effects can be limited and the necessity to spray on smooth surfaces to obtain homogeneous coatings can be avoided. Suspension particle velocities up to $800 \mathrm{~m} / \mathrm{s}$ have been measured, enabling to spray on rough surfaces (Ref 18). Beside experimental

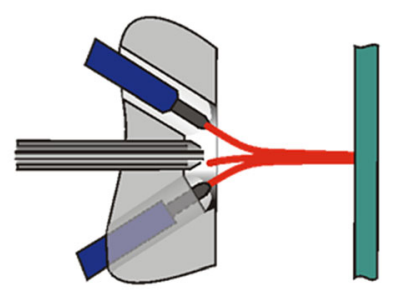

(a)

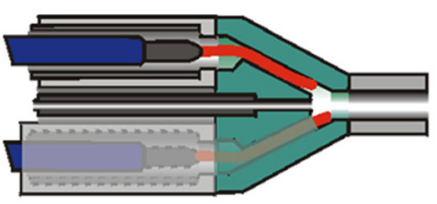

(c)

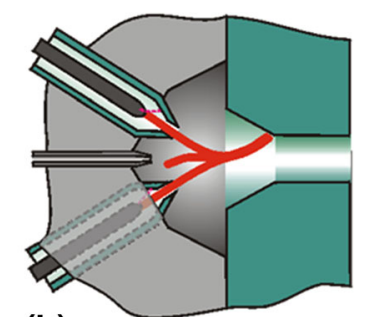

(b)

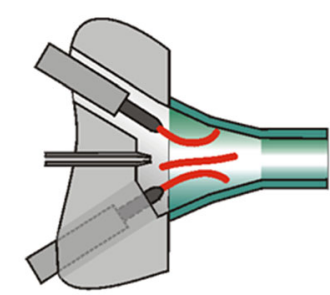

(d)
Fig. 1 Multiple-arc plasma generators with merging arcs: (a) Pfender, (b) Marantz, and with separate arcs: (c) Mühlberger/ Mettech, d) Fukanuma (Ref 4) measurements, modeling work was done to deliver insight into the interaction of the plasma with droplets and particles (Ref 19). Moreover, the Axial $\mathrm{III}^{\mathrm{TM}}$ torch was also used for solution precursor plasma spraying (SPPS). Ozturk et al. modeled this process and found that axial injection results in more rapid heat-up and precipitation than transverse injection (Ref 20).

Besides diagnostic and modeling work to determine inflight feedstock characteristics, the properties of the plasma jet generated by the Axial $\mathrm{III}^{\mathrm{TM}}$ torch were hardly investigated yet to the best knowledge of the authors. Thus, the focus of this work is the determination of the electrical parameters and their impact on the plasma jet characteristics for this system. The applied diagnostic tools are explained in detail. The following investigations were carried out:

- High-resolution current-voltage measurements,

- Tomographic determination of the plasma jet shape and initial calculation of the temperature field,

- High-speed camera imaging to correlate tomography results and current-voltage measurements,

- High-speed camera mirror optics to investigate the plasma emission inside the generator and to validate high-speed camera and tomography data,

- Ultraviolet imaging to obtain indications on the distribution of plasma gas species.

\section{Experimental Methods}

\section{Plasma Spray Environment}

The parameters for the plasma generator (Axial $\mathrm{III}^{\mathrm{TM}}$ ) studied in this work are summarized in Table 1 . The carrier

Table 1 Parameters for the plasma generator (Axial $\mathrm{III}^{\mathrm{TM}}$ )

\begin{tabular}{|c|c|c|c|c|c|}
\hline Case & $I / 3, \mathrm{~A}$ & Ar, slpm & $\mathrm{N}_{2}$, slpm & $\mathrm{H}_{2}$, slpm & Nozzle diam., setup \\
\hline 1 & 250 & 180 & 36 & 24 & $\begin{array}{l}3 / 8^{\prime \prime} \\
t \approx 32 \mathrm{~h}\end{array}$ \\
\hline 2 & 230 & $\ldots$ & 112 & 38 & $\begin{array}{l}3 / 8^{\prime \prime} \\
t \approx 32 \mathrm{~h}\end{array}$ \\
\hline 3 & 230 & $\ldots$ & 112 & 38 & $\begin{array}{l}3 / 8^{\prime \prime} \\
t<5 \mathrm{~h}\end{array}$ \\
\hline 4 & 250 & 180 & 36 & 24 & $\begin{array}{l}3 / 8^{\prime \prime} \\
t<5 \mathrm{~h}\end{array}$ \\
\hline 5 & 230 & $\ldots$ & 112 & 38 & $\begin{array}{l}9 / 16^{\prime \prime} \\
t<5 \mathrm{~h}\end{array}$ \\
\hline 6 & 230 & $\ldots$ & 112 & 38 & $\begin{array}{l}5 / 16^{\prime \prime} \\
t<5 \mathrm{~h}\end{array}$ \\
\hline
\end{tabular}

slpm standard liters per minute 
gas flow rate was 15 standard liters per minute (slpm) argon in addition to the plasma gas, except in case 4 where a reduced flow of $2 \mathrm{slpm}$ was used and $15 \mathrm{slpm}$ for comparison. In cases 3 to 6 , a new cathode-anode setup $(t<5 \mathrm{~h})$ was used in contrast to cases 1 and 2 , where a used cathode-anode setup $(t \approx 32 \mathrm{~h}$ ) was utilized. Cases 5 and 6 are variations of case 3 employing a different diameter of the nozzle throat. The setup for all experiments was a complete Axial III $^{\mathrm{TM}}$ plasma generator with three EPP-601 electrical power sources (ESAB AB, Laxå, Sweden).

\section{High-Resolution Electrical Measurements}

All electrical measurements were performed with the following equipment:

- Current measurements with Chauvin Arnoux current clamp PAC 22, 0-1.4 kA DC, output $1 \mathrm{mV} / \mathrm{A}$, accuracy $\leq 1.5 \%(0-150 \mathrm{~A}$ DC),$\leq 2 \%(200-800 \mathrm{~A} \mathrm{DC})$; $3 \mathrm{x}$ single-current cathode measurement, $1 \mathrm{x}$ singlecurrent anode measurement (total current)

- Voltage measurements with Testec TT-SI 9001 differential probe $(1 / 100), \pm 700 \mathrm{~V}, 25 \mathrm{MHz}$ bandwidth, accuracy $\pm 2 \%$; $3 \mathrm{x}$ single-voltage cathode-anode measurement

- Data processing with Multi_Detect_Control_MDC1_CGS $\left(4 \times 10^{7}\right.$ samples per second $\rightarrow$ $\Delta t=25 \mathrm{~ns}, 12$ bit, 8 channels), total recording time $32 \mathrm{~ms}$

- Simultaneous triggering of the high-speed camera system (pco.dimax HS4) with pulse generator LeCroy LW120

The recorded measurement data are further evaluated (for example power, characteristic frequencies, etc.) by means of standard calculation tools. On the one hand, the voltage signals (with impressed current) were characterized determining characteristic values such as maxima, minima, average and mean roughness values $R_{\mathrm{a}}$ and $R_{\mathrm{q}}$ (similar to surface characterization to describe the deviation from the average). For this purpose, the $1 \mathrm{~ms}$ data frames from all 32 stacks of the MDC1 device were evaluated. On the other hand, the voltage signal was subjected to a classical Fast Fourier Transformation (FFT analysis) using a Matlab-tool box and self-programmed Matlab and Delphi codes. The system typical frequencies with the corresponding amplitudes were determined again based on all $1 \mathrm{~ms}$ data frames from the 32 stacks. In principle, these system typical frequencies could have been also obtained by FFT analysis of the acoustic signal or by FFT analysis of the plasma flame length. However, as these signals are coupled to the electrical power and thus to the voltage, such analyses do not mean any additional gain in knowledge.

\section{Computer Tomography}

The shape of the plasma jet and the temperature distribution inside were investigated by computer tomography without powder injection. The tomography setup consisted of two charge-coupled device (CCD) cameras (pco.pixelfly series by PCO AG Kelheim, Germany) mounted at two different angles (Fig. 2), each one equipped with a narrowband interference filter with $10 \mathrm{~nm}$ spectral width. Considering the studied plasma gas compositions, interference filters centered at 694 and $766 \mathrm{~nm}$ with full widths at half maximum (FWHM) of $10 \mathrm{~nm}$ were chosen, in combination with grey filters with an optical density (OD) of 2 . These wavelengths were selected with respect to the characteristic spectrum of a plasma with Ar as the main constituent. They are not too far from each other so that the Boltzmann method can be applied for the determination of temperatures. When rotating the two CCD cameras by $180^{\circ}$ around the jet axis, images were taken at 60 incremental angular positions. This allows the tomographic reconstruction of a three-dimensional emissivity distribution in both of the selected narrow spectral ranges. The reconstructed image contains 120 cross sections and has a downstream extension of approx. $40 \mathrm{~mm}$ at a resolution of $0.32 \mathrm{~mm} /$ pixel. This reconstruction, however, requires that the jet is optically thin and virtually stationary during the scanning time of 2-3 min. Such conditions can be assumed as approximately fulfilled since the characteristic fluctuations of the Axial III ${ }^{\mathrm{TM}}$ plasma generator are on a relatively low level similar as it was found already for a cascaded three-cathode torch (Ref 21). Assuming local thermodynamic equilibrium, the emissivity of the plasma gas is a known function of the gas temperature according to a standard calculation based on the Saha equation. Details can be found elsewhere (Ref 22-27). In order to estimate the temperature

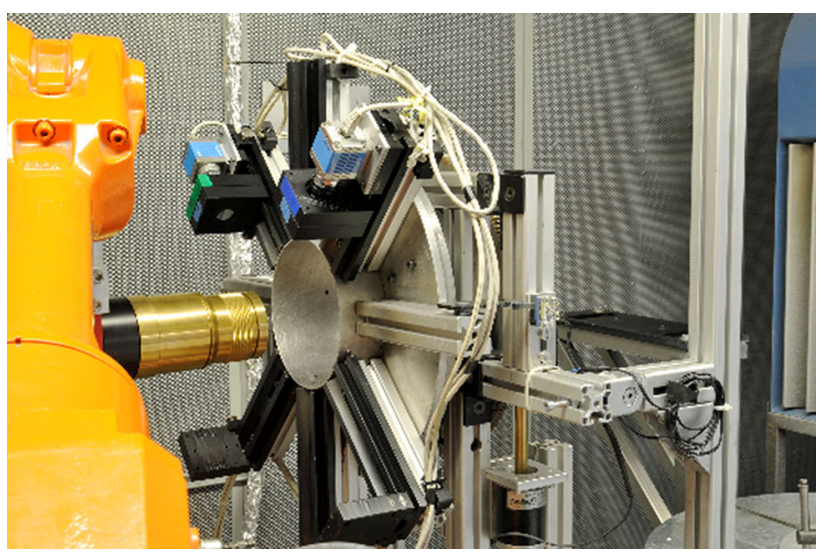

Fig. 2 Tomography setup to determine the shape of the plasma jet and the temperature distribution 
distribution at the nozzle exit under conditions of a high gas flow, the obtained tomographic reconstructions were readjusted considering the gas mass flow and the net power in the respective experimental cases.

\section{High-Speed Camera}

The images taken by the high-speed camera complemented the results of the current-voltage measurement and tomographic investigations. The high-speed camera images were taken at the following settings:

- Camera Type: pco.dimax HS4 (12 bit)

- Image size horiz./vert.: 706/506

- Exposure/delay: $0.01 \mathrm{~ms} / 0 \mathrm{~ms}$

- Image refresh rate: 16,071 frames per second $\rightarrow \Delta t=$ $62.22 \mu \mathrm{s}$

- Scale: $78.13 \mu \mathrm{m} /$ pixel

- Simultaneous triggering of Multi_Detect_Control_MDC1_CGS with a pulse generator LeCroy LW120

The triggering allowed to correlate the plasma jet shape with the instant current-voltage data. Moreover, self-programmed image processing software (edge filter, binary filter, etc.) was used.

\section{High-Speed Camera Mirror Optics}

The high-speed camera mirror optics was applied to look directly into the nozzle of the plasma generator and detect the emission distribution generated by the three separate plasma generators. Thus, the fluctuations of the overall plasma jet shape can be observed directly. Moreover, first comparisons with the tomographic results (contour plane plots) are possible. Below, the parameters and the setup (Fig. 3) of the high-speed camera mirror-optics are given:

- Camera Type: pco.dimax HS4 (12 bit)

- Image size horiz./vert.: 206/206

- Exposure/delay: $0.05 \mathrm{~ms} / 0 \mathrm{~ms}$

- Maximum possible image refresh rate: 50,040 frames per second $\rightarrow \Delta t=19.984 \mu \mathrm{s}$; however, considering the compelling condition $\Delta t_{\text {exposure }} \leq \Delta t_{\text {readout }}$, a higher image refresh time of $\Delta t=50 \mu$ s was used.

- Scale: $121.67 \mu \mathrm{m} /$ pixel

In addition, self-programmed image processing software (composite images with process image and numerical data, plasma position with respect to the plasma generator nozzle exit) was used to recalculate the plasma shape data and to represent the results.

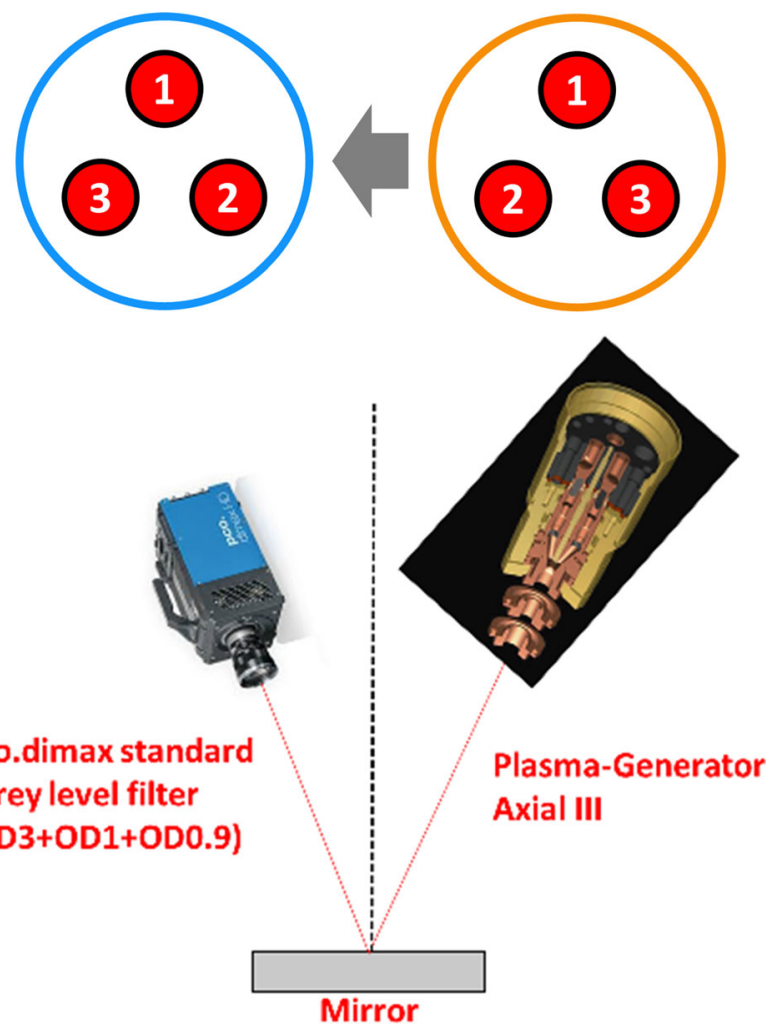

Fig. 3 Setup of mirror-optics to detect the emission distribution inside the plasma generator, OD denotes the optical density of the applied filters, the numbers indicate the three cathode-anode units; torch graphics taken from Ref 9

\section{UV-Camera}

To characterize the plasma also in the range of high energetic ultraviolet (UV) emission, a UV camera was combined with three different UV bandpass filters. The following parameters were used (FWHM: full width at half maximum):

- Camera Type: pco.ultaviolet (14 bit)

- Image size horiz./vert.: 348/260

- UV bandpass filters: 308 nm, FWHM 20 nm, UV-B (near UV)

UV bandpass filters: $248 \mathrm{~nm}$, FWHM $20 \mathrm{~nm}$, UV-C (middle UV)

UV bandpass filters: $193 \mathrm{~nm}$, FWHM $20 \mathrm{~nm}$, UV-C (far UV)

- Scale: $1000 \mu \mathrm{m} /$ pixel

The intensity distributions in these three wavelength windows can give indications on the special distribution of the plasma gas species. Also, temperature distributions of the plasma could be calculated (not shown in this work). Furthermore, information on UV emission is relevant for occupational safety. 


\section{Results and Discussion}

\section{Comparison of a Used and a New Cathode-Anode Setup}

A used $(t \approx 32 \mathrm{~h}$, case 2$)$ and an almost new cathodeanode set $(t<5 \mathrm{~h}$, case 3$)$ were compared at the same operating conditions, see Table 1. Figure 4 shows the time courses of current and power for both cases. The individual colors denote:

- Electrical power $\left(P_{1}=U_{1} \cdot I_{1}\right)[\mathrm{kW}]$ : green

- Electrical power $\left(P_{2}=U_{2} \cdot I_{2}\right)[\mathrm{kW}]$ : blue

- Electrical power $\left(P_{3}=U_{3} \cdot I_{3}\right)[\mathrm{kW}]$ : magenta

- Total electrical power $\left(P=U \cdot I, U=1 / 3 \cdot \Sigma U_{i}, I=\Sigma I_{i}\right)$ $[\mathrm{kW}]$ : black

The average power of the three single cathode-anode units \#1-3 (i.e., the voltage demand) and thus the total power was higher for the new cathode-anode set, while the amplitude of the fluctuations were similar. In case 2, however, the power of the cathode-anode unit \#2 was significantly lower compared to the other two units \#1 and \#3, see the characteristic values of the power-time courses in Fig. 5. The lower variation for this single unit \#2 may be because the arc root dug into the anode wall and formed pits so that the arc root was anchored and fluctuated less (Ref 28).

Since the operation mode of the torch was the constant current option, the power fluctuations were caused primarily by variations of the voltage. Hence, Fourier analyses of the voltage time courses were carried out for the single cathode-anode units \#1-3 each in case $2(t \approx 32 \mathrm{~h})$ and case $3(t<5 \mathrm{~h})$. The comparison of the voltage harmonics at high frequencies $f>2 \mathrm{kHz}$ revealed that the arc fluctuation of the cathode-anode unit \#2 was different to some extent than for the other units \#1 and \#3 in case 2 and for all three units in case 3 , respectively. The maximum amplitude $U_{\max }$ is the lowest and the corresponding
Fig. 4 Time courses of the single unit and the total powers during a data recording time of 2 ms; top: used cathode-anode set $(t \approx 32 \mathrm{~h}$, case 2$)$, bottom new cathode-anode set $(t<5 \mathrm{~h}$, case 3)

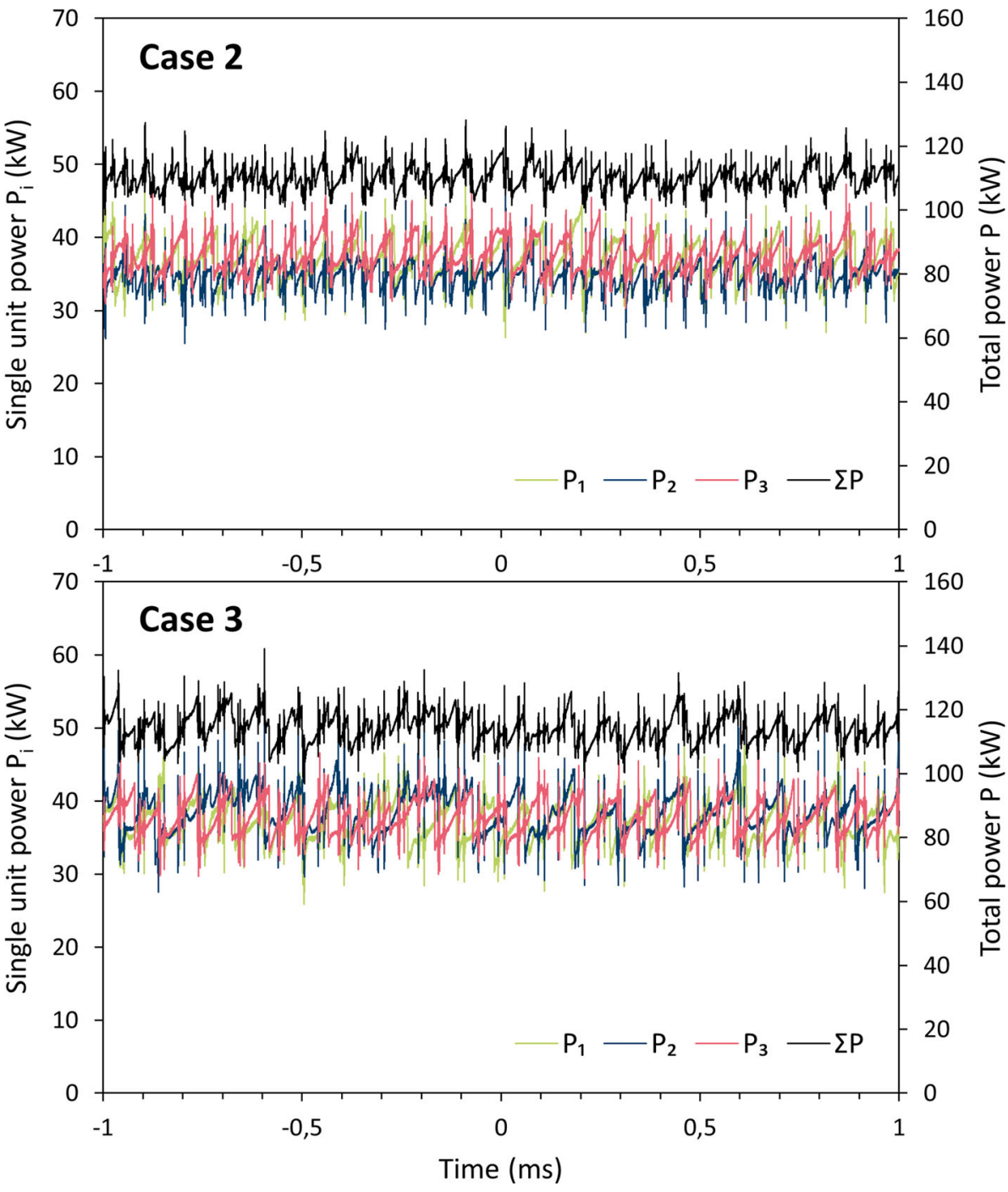


frequency $f\left(U_{\max }\right)$ is the highest, see Fig. 6. This confirms the assumption that the arc root is fixed by the formation of pits on the anode wall due to wear.

The tomographic reconstruction provides a time-averaged three-dimensional distribution of the plasma gas temperature. Figure 7 shows the tomographic results of the three-dimensional temperature fields in the plasma jets at different torch setups. Besides the discrete iso-contours of the temperatures, the nozzle geometries (throat and exit planes) are delineated. The jets could be detected downstream from a distance of $3 \mathrm{~mm}$ to the nozzle exit planes. Figure 7(a) and (b) give the comparison between the used cathode-anode set $(t \approx 32 \mathrm{~h}$, case 1$)$ and the cathodeanode set in mint condition $(t<5 \mathrm{~h}$, case 4). Figure 7(c) and (d) give the comparison between the same hardware setups, however at a more powerful plasma parameter (case 2 and case 3, see Table 1).
It is evident that the plasma jet shows three intensity lobes each associated with one of the three cathode-anode units. As there is no plasma gas swirl as employed in the three-cathode Triplex torch (Ref 21), the lobes were straight and not helical. With the used cathode-anode set, one of these lobes (\#2) was smaller while they exhibited similar dimensions using the set in mint condition. This is obvious for both investigated plasma parameters. Such asymmetry was already found in the time traces of the power, see Figs. 4 and 5. It is suggested that this was because the respective cathode-anode pair showed indications of wear. In fact, the cathodes of the used electrode set $(t \approx 32 \mathrm{~h})$ showed indications of wear to different extents, Fig. 8.
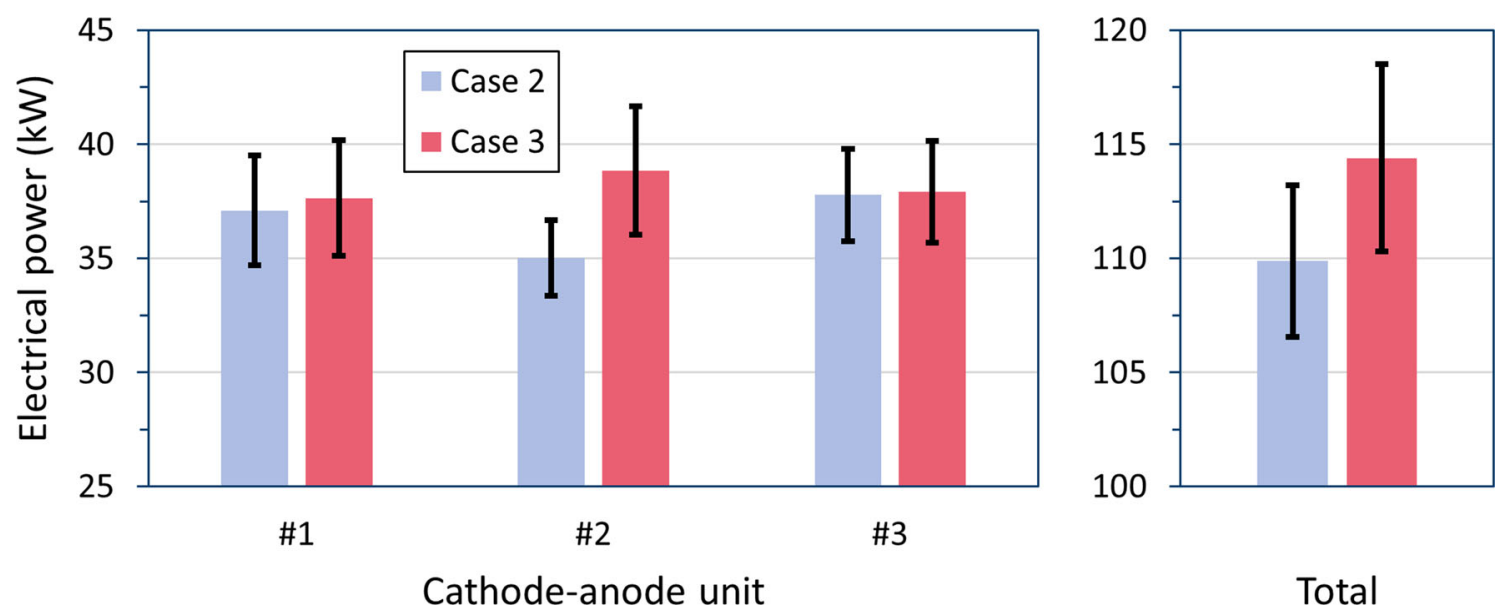

Total

Fig. 5 Characteristic values of the power-time courses given in Fig. 4 for the used cathode-anode set $(t \approx 32 \mathrm{~h}$, case 2$)$ and the new cathode-anode set $(t<5 \mathrm{~h}$, case 3$)$; the columns represent the average electrical power, the error bars depict the root mean squared roughness. Note the zero point suppression of the vertical axes
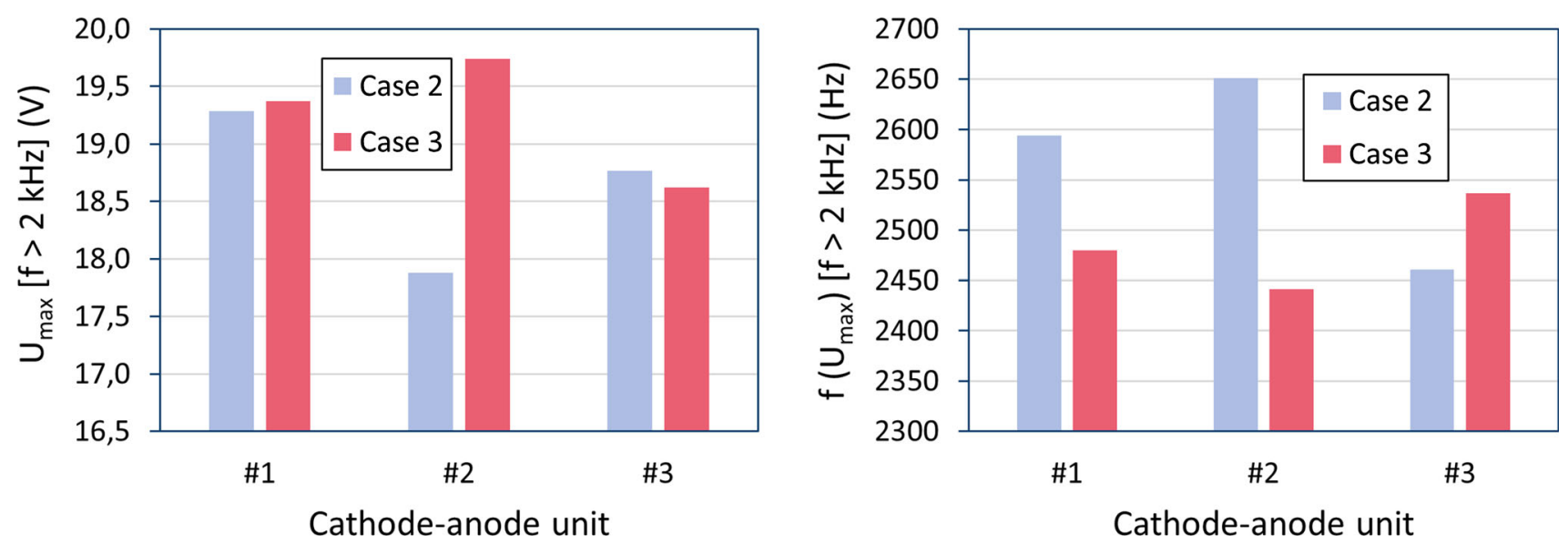

Fig. 6 Comparison of the maximum voltage harmonics at high frequencies $f>2 \mathrm{kHz}$ resulting from Fourier analyses for all three cathodeanode units in case $2(t \approx 32 \mathrm{~h})$ and case $3(t<5 \mathrm{~h})$, respectively. Note the zero point suppression of the vertical axes 


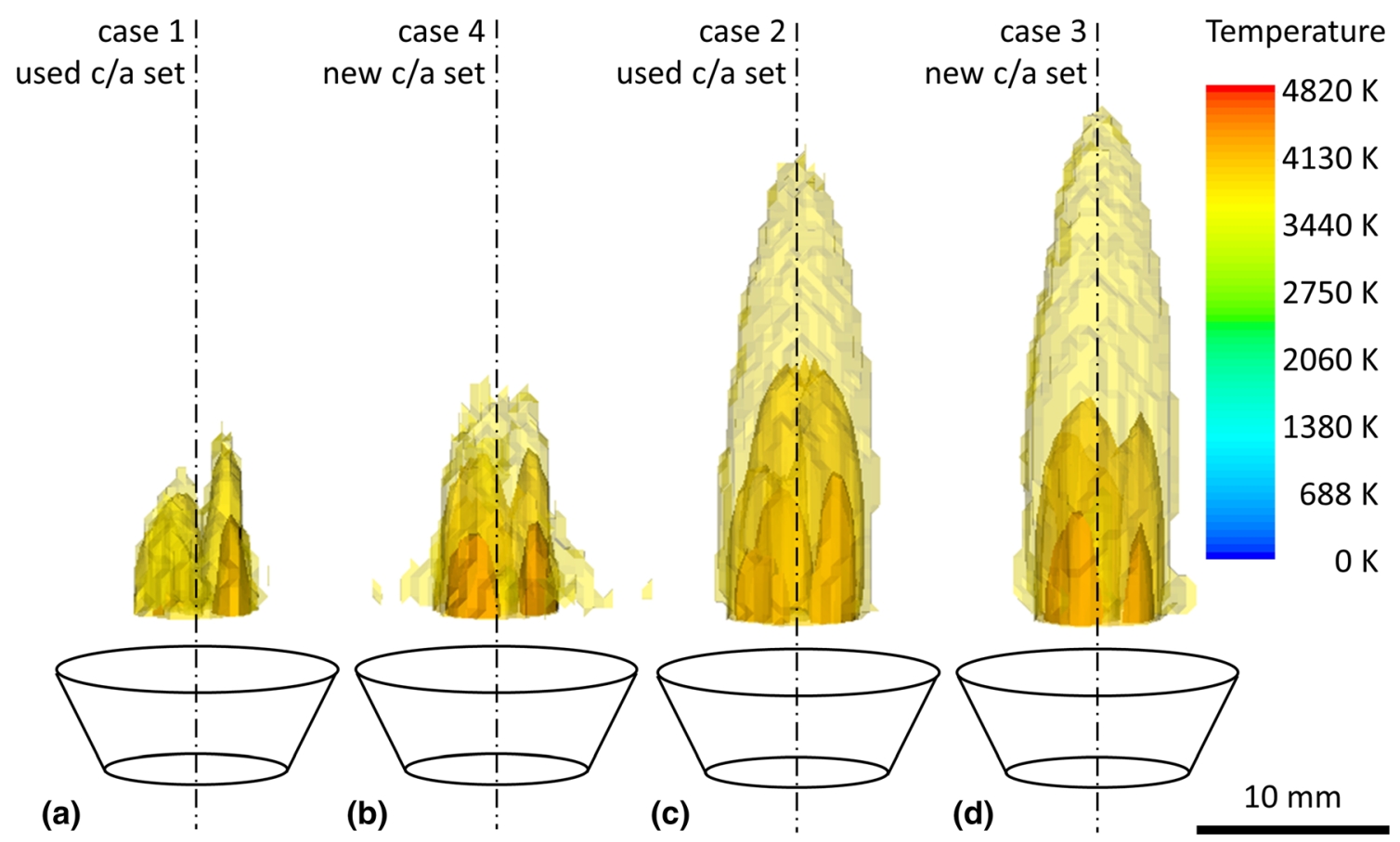

Fig. 7 Tomographic 3D-reconstruction of the temperature field in the plasma jet at two different torch parameters using the $3 / 8^{\prime \prime}$-nozzle; (a) used cathode-anode set $(t \approx 32 \mathrm{~h}$, case 1$)$, (b) new cathode-

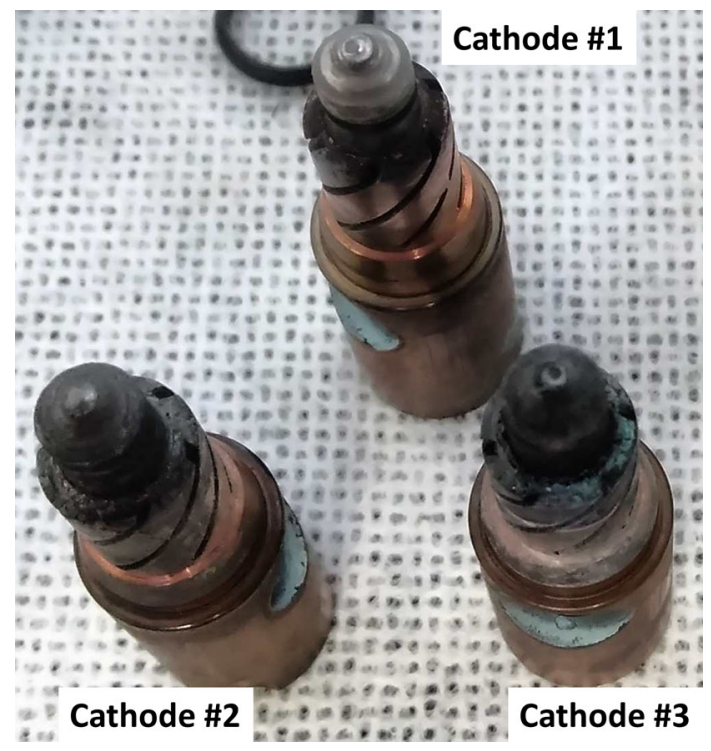

Fig. 8 Cathodes of the used electrode set $(t \approx 32$ h) showing indications of wear to different extents

\section{Comparison of Different Nozzle Throat Diameters}

Figure 9 shows the comparison of the tomographic results for the three different nozzle throat diameters of $3 / 8^{\prime \prime}$, $9 / 16^{\prime \prime}$, and $5 / 16^{\prime \prime}$, each in combination with the new cathode-anode set, cases 3, 5, and 6 (see Table 1). The plasma gas velocities were changed by altering the nozzle anode set $(t<5 \mathrm{~h}$, case 4$)$, (c) used cathode-anode set $(t \approx 32 \mathrm{~h}$, case 2), (d) new cathode-anode set $(t<5 \mathrm{~h}$, case 3$)$

diameter. Since the gas flows were the same in each case, the plasma density was directly affected. Using the largest nozzle, the plasma density in the jet was the lowest. As the electrical power was the same in the three cases, the mass specific enthalpy of the plasma gas was the largest. This led to the highest emission intensity as it is evident in Fig. 9. In all three cases, the triple intensity lobes were pronounced.

\section{Effect of Power Asymmetry}

Power asymmetry was simulated by varying the three individual currents in case $4\left(I_{1}=I_{2}=I_{3}=250 \mathrm{~A}\right)$ one after the other $\left(I_{1}=220 \mathrm{~A}, I_{2}=220 \mathrm{~A}, I_{3}=220 \mathrm{~A}\right)$. Figure 10 gives time-averaged contour plots of the plasma temperature for the cross-sectional plane $3 \mathrm{~mm}$ downstream from nozzle exit resulting from the tomographic reconstruction of the temperature field in the plasma jet. The power asymmetries cause slight eccentricities of the temperature distributions in the center of the jet where the feedstock powder is injected. Thus, the power of the single cathodeanode units should be monitored carefully to ensure an optimum feedstock treatment and to avoid any asymmetries in the deposition process.

\section{Temporal Plasma Fluctuations}

Figure 11 shows three sequential side-on views of the plasma jet taken by the high-speed camera in time intervals 
Fig. 9 Tomographic 3Dreconstruction of the temperature field in the plasma jet using the new cathode-anode set $\left(t<5\right.$ h); (a) $3 / 8^{\prime \prime}$-nozzle (case 3), (b) $9 / 16^{\prime \prime}$-nozzle (case 5), (c) $5 / 16^{\prime \prime}$-nozzle (case 6)
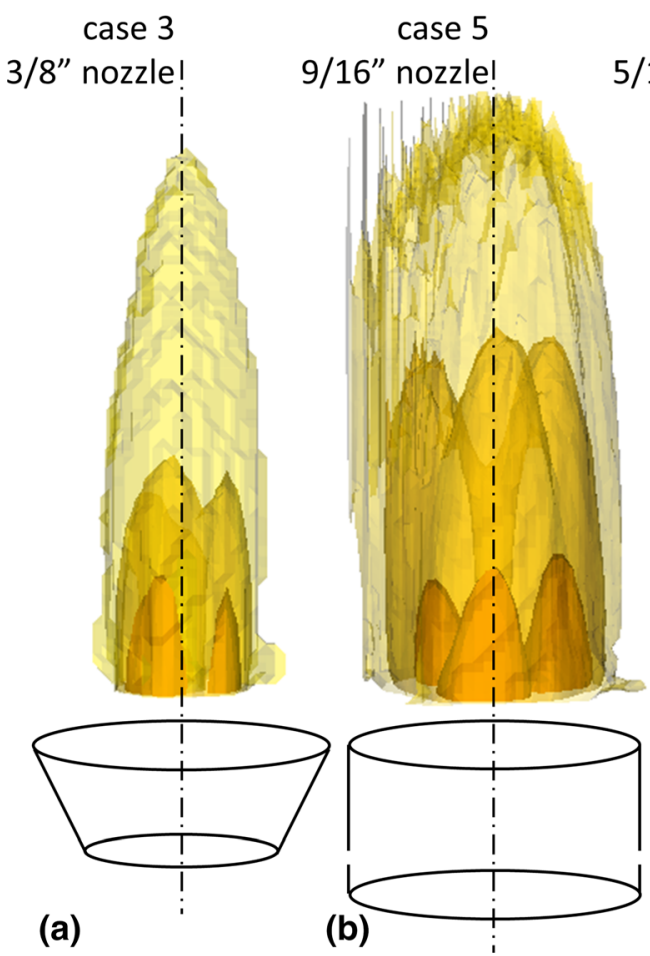

case 6

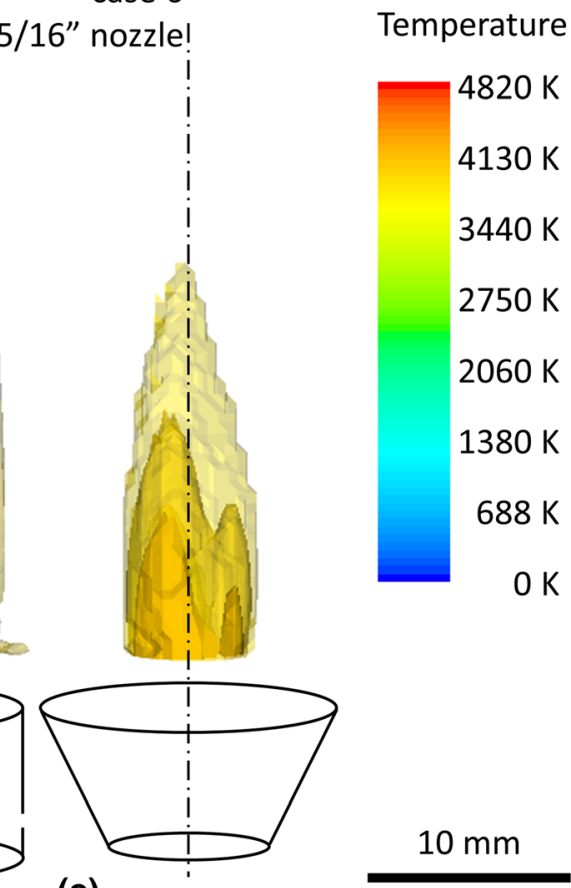

(c)
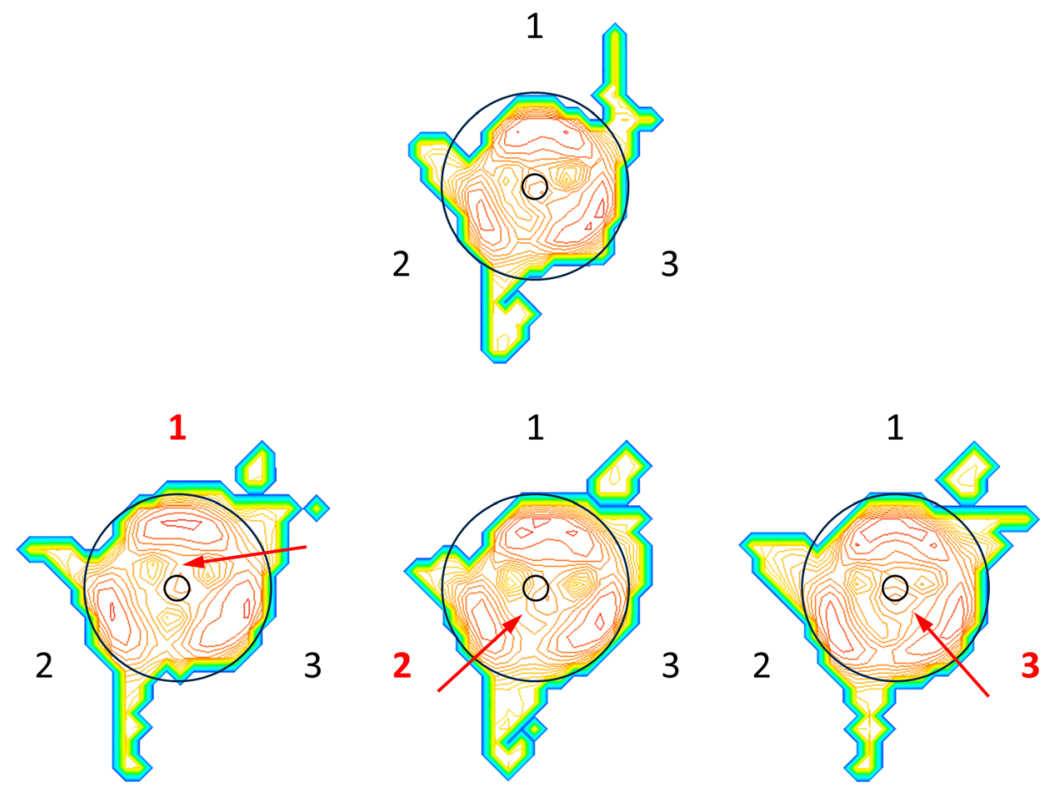

Temperature (K)

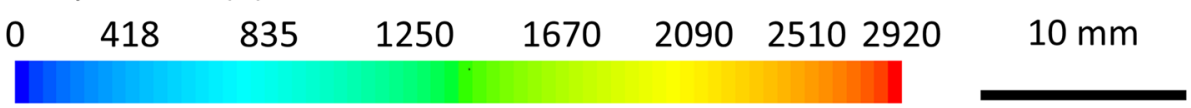

of $\Delta t=62.22 \mu \mathrm{s}$. The length scale is depicted at the bottom of the figure corresponding to $78.13 \mu \mathrm{m} /$ pixel. For each image, the instantaneous total electrical power $(P=$ $\left.U \cdot I, U=1 / 3 \cdot \Sigma U_{i}, I=\Sigma I_{i}\right)$ is indicated which was obtained by triggering the voltage-current measurements and the high-speed camera. These values reflect the fast fluctuations in time of the plasma power as mentioned above (see Fig. 5). Besides the original images, also transformations to pseudo-rainbow colors and Sobel-filtered images are shown. The pseudo-rainbow colors give an enhanced 

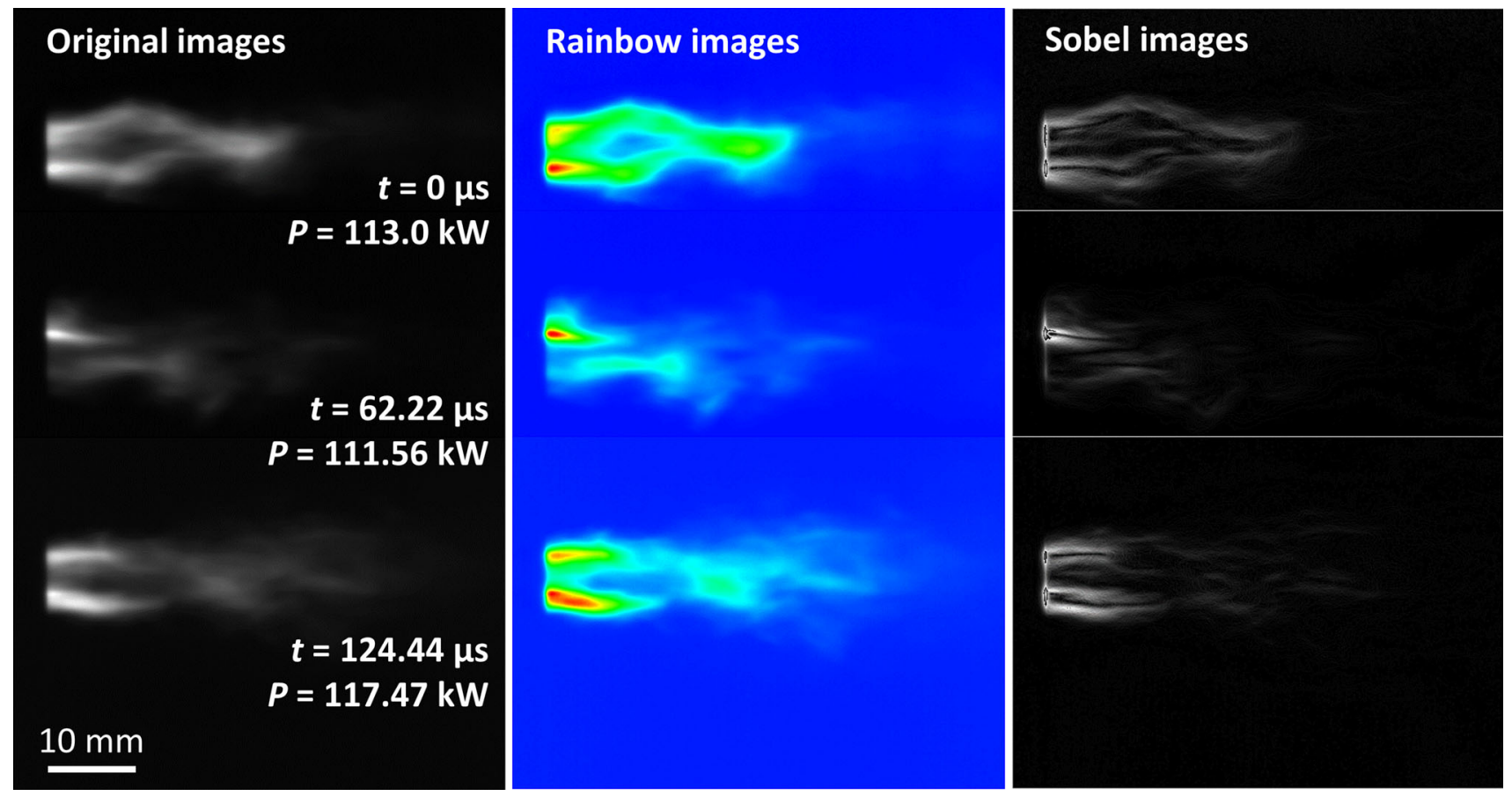

Fig. 11 Sequential high-speed side-on images of the plasma jet in case 3, exposure time $10 \mu$ s, image refresh rate 16,071 frames per second $\rightarrow$ $\Delta t=62.22 \mu \mathrm{s}$; left: original images; middle: pseudo-rainbow rainbow color images, right: Sobel-filtered images

contrast between pixels with small brightness differences, while the Sobel operator is an edge detection filter calculating the first derivative of the pixel brightness values while simultaneously smoothing orthogonally to the direction of the derivative (Ref 29). Thus, strong intensity gradients appear bright, while intensity extrema look dark. In the first part of the jet downstream from nozzle exit, the plasma jet showed triple temperature distributions. This was evident already from the tomographic results which, however, were time averaged. Here, the high time resolution images prove that the plasma emission intensities were also subject to fast temporal variations. Obviously, the arc fluctuations at the three individual cathode-anode units affected the expanding jet and were not equalized entirely by merging the three plasma jets.

Three intensity line scans in radial direction were made at positions of 10,20 , and $30 \mathrm{~mm}$ downstream from nozzle exit using the three sequential high-speed camera images in Fig. 11. The distributions of the plasma intensities along each of these lines are given in Fig. 12. This evaluation was done by means of self-programmed image evaluation. It is evident that the emission intensity of the plasma showed a triple characteristic. The three expanding jets merged only at $30 \mathrm{~mm}$ distance to the nozzle exit. The total electrical power $\left(P=U \cdot I, U=1 / 3 \cdot \Sigma U_{i}, I=\Sigma I_{i}\right)$ is indicated additionally for each time instance. These values show a similar trend to the sizes of the areas under the radial intensity profiles.

\section{Effect of Carrier Gas Flow}

Figure 13 gives sequential high-speed camera mirror-optical images edited by self-programmed image analysis to compare the plasma jet formation in case 4 (see Table 1) at two different carrier gas flows of 15 and $2 \mathrm{slpm}$. A scale of $121.67 \mu \mathrm{m} /$ pixel was used. In each image the nozzle exit diameter and the throat diameter were superimposed as solid and dash-dotted lines, respectively. The smallest inner circles depict the diameter of the powder injector. It must be noted that the obtained images are mirror-inverted, see Fig. 3. Obviously, at the higher carrier gas flow, the hot plasma jet was more constricted as a thicker cold boundary layer was formed at the wall of the torch nozzle.

\section{Spatial Distribution of Plasma Gas Constituents}

Figure 14 shows side-on images of the plasma jet UV emission (case 4) in the three investigated wavelength windows

- UV-B (near UV) image (band pass filter $308 \mathrm{~nm}$, FWHM $20 \mathrm{~nm})$

- UV-C (middle UV) image (band pass filter $248 \mathrm{~nm}$, FWHM $20 \mathrm{~nm}$ )

- UV-C (far UV) image (band pass filter 193 nm, FWHM $20 \mathrm{~nm}$ )

The exposure time was $1 \mathrm{~ms}$ at each wavelength window.

Plasma radiation in the high energetic UV-range is emitted only by gas species which are at least single 


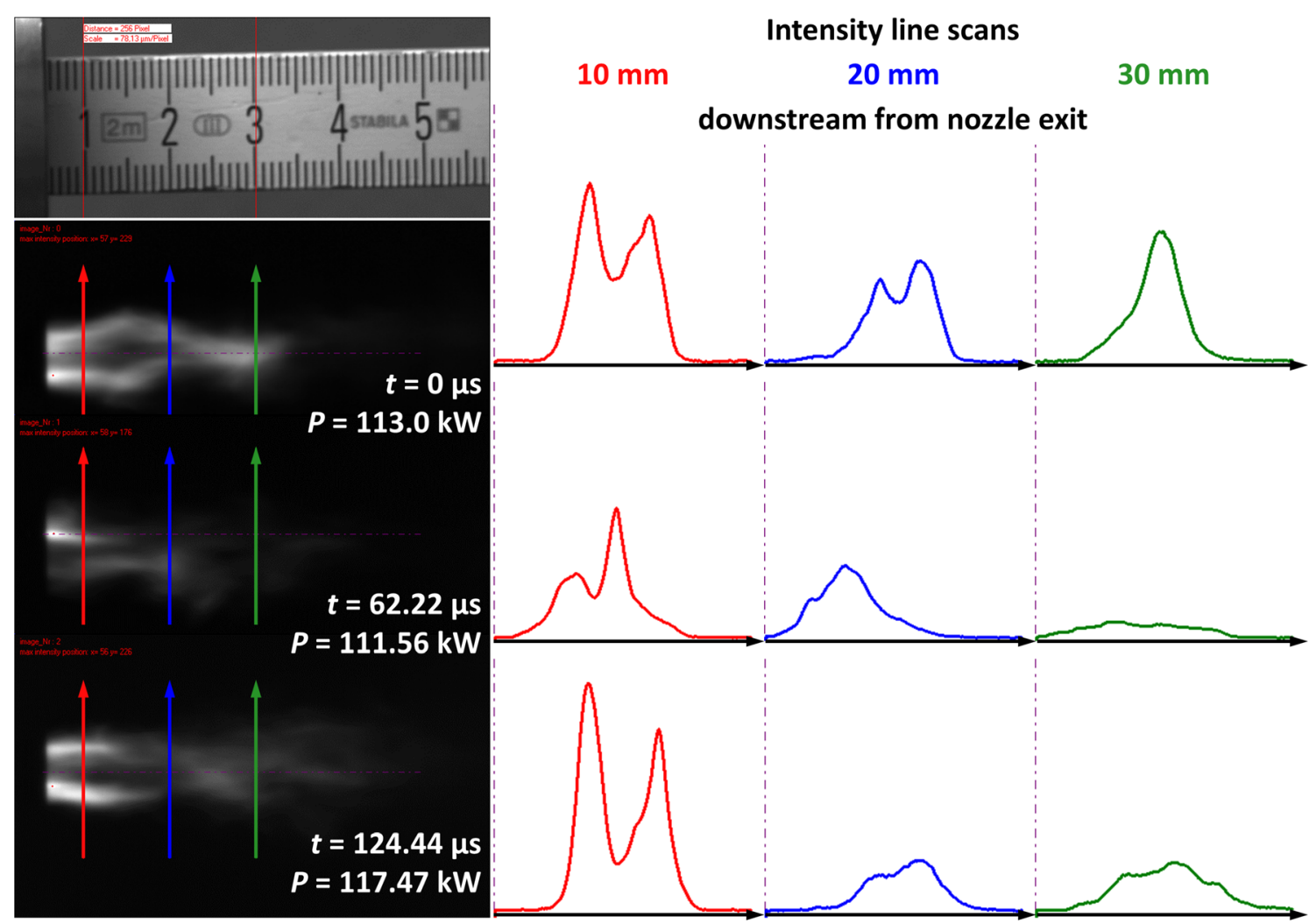

Fig. 12 Intensity line scans of the three sequential high-speed images given in Fig. 11 at positions $10 \mathrm{~mm}$ (red), $20 \mathrm{~mm}$ (blue), and $30 \mathrm{~mm}$ (green) downstream from nozzle exit (case 3)

ionized, i.e., in case 4 , this was nitrogen and argon. Consulting the NIST database (Ref 30 ) reveals that in the wavelength window around $308 \mathrm{~nm}$, the emission is dominated by several $\mathrm{Ar}^{+}$lines. Nearby $248 \mathrm{~nm}$, many $\mathrm{Ar}^{+}$lines and several $\mathrm{N}^{+}$lines are present, while around $193 \mathrm{~nm}$, only $\mathrm{N}^{2+}$ lines are significant. As the intensity distributions in the three images of Fig. 14 are different to each other, this is an indication that demixing effects took place in the plasma jet. Apparently, the heavier argon ions were concentrated near the jet axis, while the nitrogen ions moved to the jet edges. A similar phenomenon is known from argon-hydrogen plasmas where a mass focusing effect is assumed (Ref 31,32$)$.

\section{Conclusions}

Several diagnostic methods were applied to characterize the plasma jet of an Axial III $^{\mathrm{TM}}$ spray torch with internal axial feedstock injection. For the investigated torch parameters, one important finding was that the plasma temperature exhibits a triple distribution with three straight lobes which are arranged around the jet axis. This was found applying all three nozzles with different throat diameters which are available for this torch. As the feedstock is injected axially into the jet center, it can be expected that the particles are kept effectively in the plasma. However, it is obvious that the jet center does not show the highest enthalpies compared to the three lobes around. They are merged only at a distance of approx. $30 \mathrm{~mm}$ downstream from the nozzle exit where the plasma has already cooled down considerably. Another important result is that the total plasma power is subject to fast temporal variations. Obviously, the triple jet characteristics and the natural fluctuations of the arcs generated by the three single cathode-anode units are not equalized entirely by merging the three plasma streams. Thus, the plasma jet is characterized by substantial inhomogeneities of the spatial temperature distribution and in terms of time.

As it is well known from single cathode plasma generators, the electrodes are exposed to wear. On the one hand, degradation leads to an overall drop of the total plasma power as found also in this work on the Axial III $^{\mathrm{TM}}$. On the other hand, asymmetries in the plasma enthalpy distribution can be formed here as wear of the three cathode-anode units is subject to a certain randomness. Thus, the total electrical torch power as well as the uniformity of the single unit's powers must be monitored carefully during operation since asymmetries of the electrical power were found to affect the plasma temperature distribution. 


\section{(a) C/G $15 \mathrm{slpm}$}
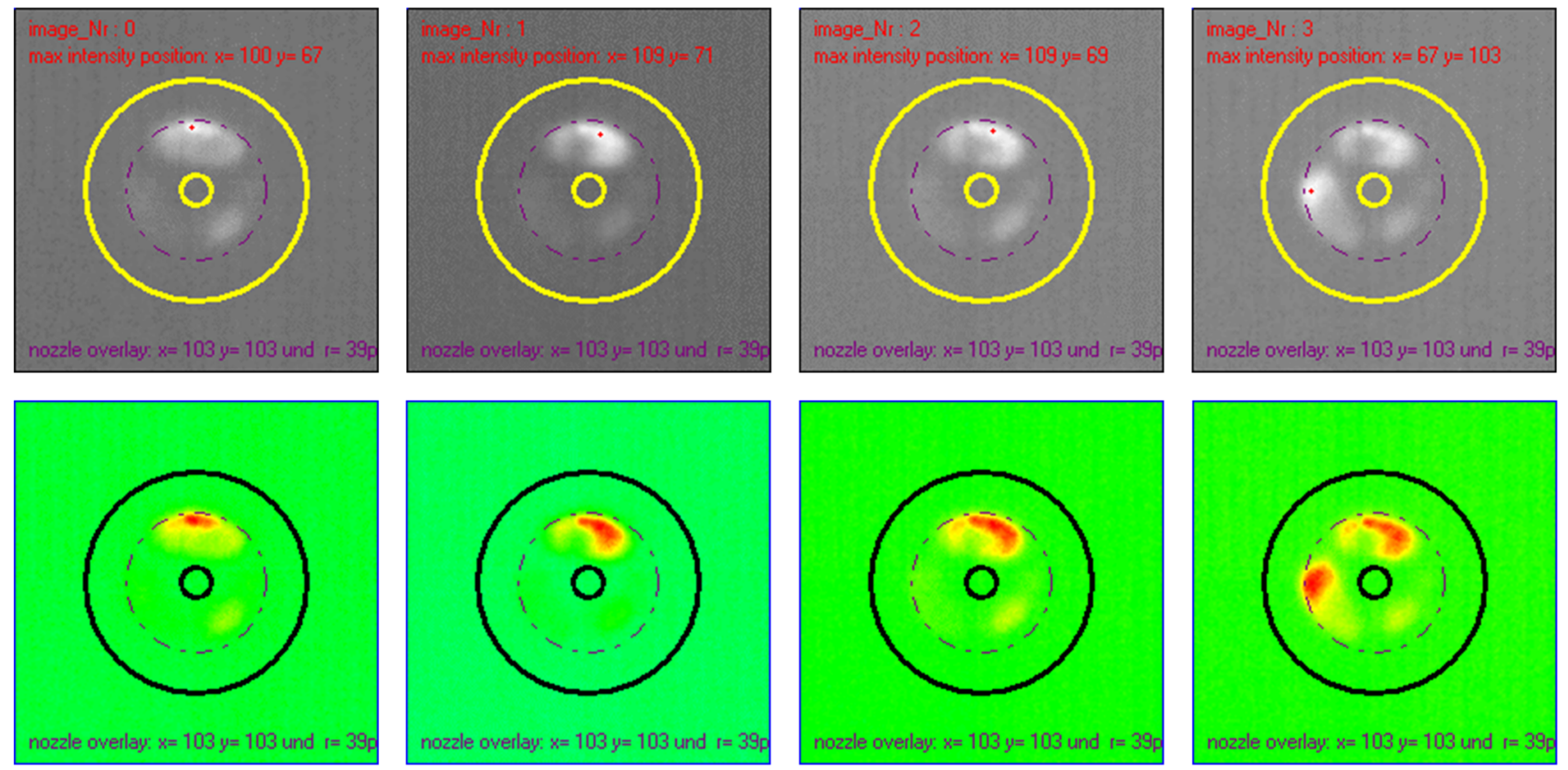

\section{(b) C/G 2 slpm}
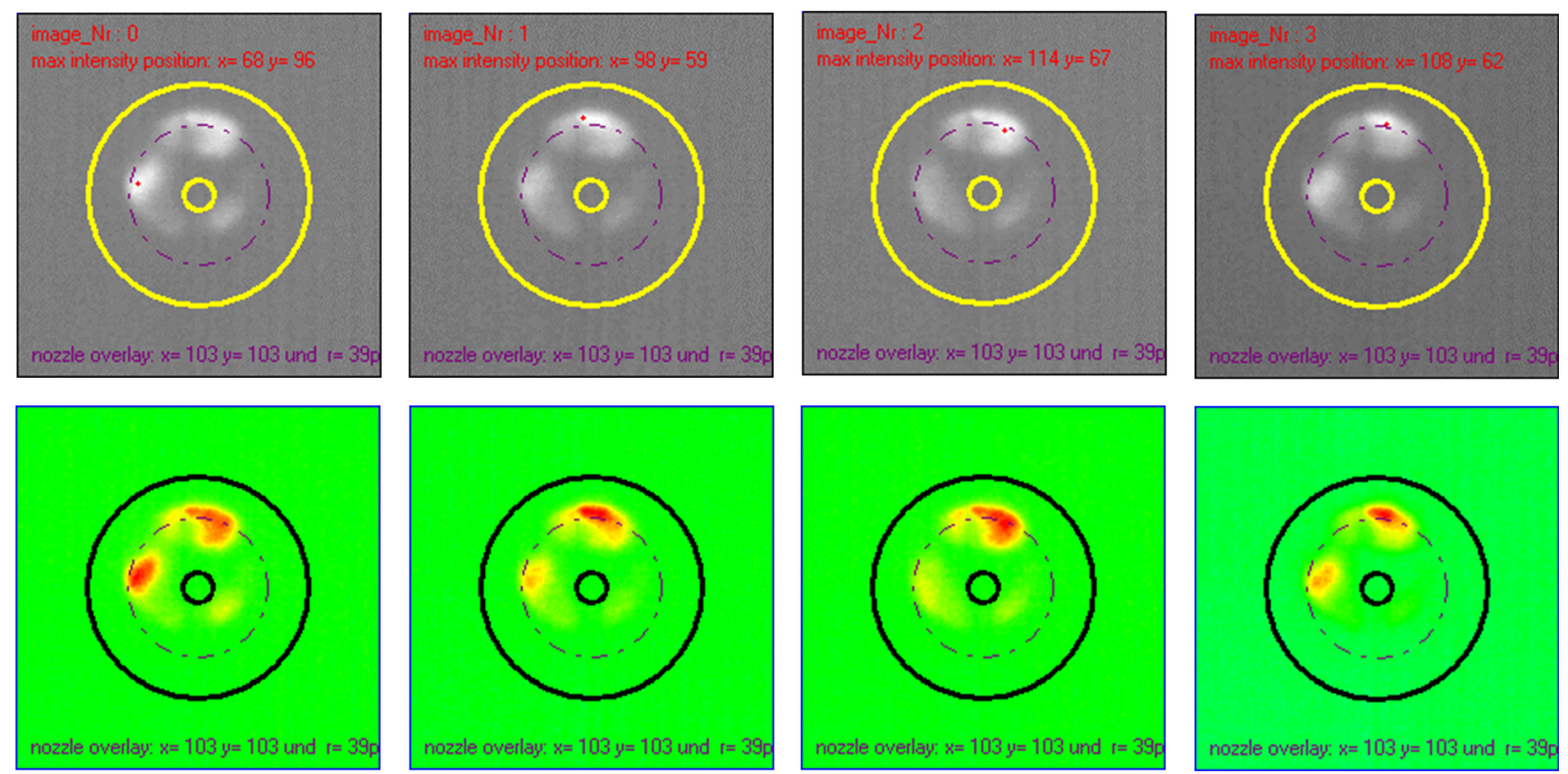

Fig. 13 Edited sequential high-speed camera mirror-optical images to compare the plasma jet formation in case 4 using two different carrier gas flows (a) $C / G=15 \mathrm{slpm}$ and (b) $C / G=2 \mathrm{slpm}$; top: original image, bottom: false color/rainbow image; 20,000 frames per second $\rightarrow \Delta t=50 \mu \mathrm{s}$

The axial carrier gas flow was also found to have an impact on the plasma jet. Higher amounts led to a certain radial constriction of the jet, which is not expected to be disadvantageous, however. But it is likely that large cold carrier gas flows decrease the plasma enthalpy to some extent. Moreover, the results suggested demixing of the plasma gas constituents. Yet, this is assumed to be not specific for the Axial $\mathrm{III}^{\mathrm{TM}}$ plasma generator as segregation effects can be expected in all plasma jets containing gas species with substantially different densities. 
Fig. 14 Side-on images of the plasma jet UV emission in three investigated wavelength windows (case 4); flow direction from left to right, exposure time $1 \mathrm{~ms}$; left: original images, right: pseudorainbow color images
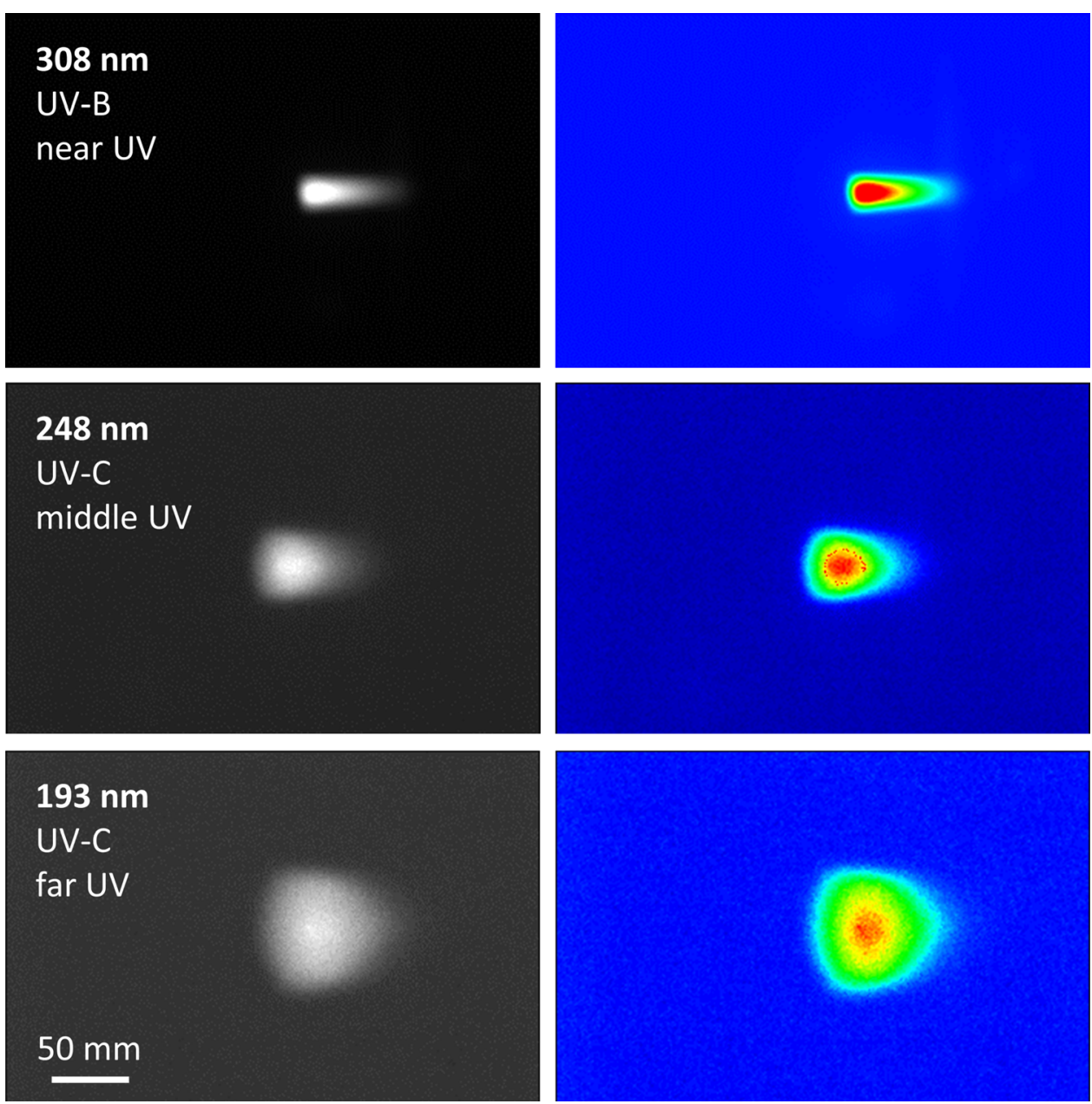

Funding Open Access funding enabled and organized by Projekt DEAL.

Open Access This article is licensed under a Creative Commons Attribution 4.0 International License, which permits use, sharing, adaptation, distribution and reproduction in any medium or format, as long as you give appropriate credit to the original author(s) and the source, provide a link to the Creative Commons licence, and indicate if changes were made. The images or other third party material in this article are included in the article's Creative Commons licence, unless indicated otherwise in a credit line to the material. If material is not included in the article's Creative Commons licence and your intended use is not permitted by statutory regulation or exceeds the permitted use, you will need to obtain permission directly from the copyright holder. To view a copy of this licence, visit http://creativecommons. org/licenses/by/4.0/.

\section{References}

1. P. Fauchais, A. Vardelle, and B. Dussoubs, Quo Vadis Thermal Spraying?, J. Therm. Spray Technol., 2001, 10(1), p 44-66

2. P. Fauchais, Understanding Plasma Spraying, J. Phys. D Appl. Phys., 2004, 37(9), p R86-R108

3. J. Schein, J. Zierhut, M. Dzulko, G. Forster, and K.D. Landes, Improved Plasma Spray Torch Stability Through Multi-electrode Design, Contrib. Plasma Phys., 2007, 47(7), p 498-504
4. J.L. Marqués, G. Forster, and J. Schein, Multi-electrode Plasma Torches: Motivation for Development and Current State-of-theArt, Open Plasma Phys. J., 2009, 2, p 89-98

5. C. Moreau, P. Gougeon, A. Burgess, and D. Ross, Characterization of Particle Flows in an Axial Injection Plasma Torch, 8th NTSC: Advances in Thermal Spray Science and Technology, 11-15 Sept. C.C. Berndt and S. Sampath Ed., ASM International, Houston, 1995, p 141-147

6. J. Mostaghimi and M.I. Boulos, Thermal Plasma Sources: How Well are They Adopted to Process Needs?, Plasma Chem. Plasma Process., 2015, 35(3), p 421-436

7. D. Waldbillig and O. Kesler, Characterization of Metal-Supported Axial Injection Plasma Sprayed Solid Oxide Fuel Cells with Aqueous Suspension Plasma Sprayed Electrolyte Layers, $J$. Power Sources, 2009, 191(2), p 320-329

8. D.A. Ross and A. Burgess, Plasma Jet Converging System, United States Patent No. 5,556,558 (1996)

9. Axial III Core Technology, https://www.mettech.com/coatingtechnology/axial-III-core-technology.php. Accessed 2 Dec 2020

10. Z. Tang, H. Kim, I. Yaroslavski, G. Masindo, Z. Celler, and D. Ellsworth, Novel Thermal Barrier Coatings Produced by Axial Suspension Plasma Spray, Thermal Spray 2011, Sept 27-29. B.R. Marple, A. Agarwal, M.M. Hyland, Y.-C. Lau, C.-J. Li, R.S. Lima, and A. McDonald Ed., DVS Media, Hamburg, 2011, p 571-575

11. D. Zhou, O. Guillon, and R. Vaßen, Development of YSZ Thermal Barrier Coatings Using Axial Suspension Plasma Spraying, Coatings, 2017, 7(8), p 120 
12. N. Markocsan, M. Gupta, S. Joshi, P. Nylén, X.-H. Li, and J. Wigren, Liquid Feedstock Plasma Spraying: An Emerging Process for Advanced Thermal Barrier Coatings, J. Therm. Spray Technol., 2017, 26(6), p 1104-1114

13. J.-K. Lee, S.-J. Park, Y.-S. Oh, S. Kim, H. Kim, and S.-M. Lee, Fragmentation Behavior of $\mathrm{Y}_{2} \mathrm{O}_{3}$ Suspension in Axially Fed Suspension Plasma Spray, Surf. Coat. Technol., 2017, 309, p 456-461

14. F. Tarasi, M. Medraj, A. Dolatabadi, J. Oberste-Berghaus, and C. Moreau, Effective Parameters in Axial Injection Suspension Plasma Spray Process of Alumina-Zirconia Ceramics, J. Therm. Spray Technol., 2008, 17(5), p 685-691

15. F. Tarasi, M. Medraj, A. Dolatabadi, J. Oberste-Berghaus, and C. Moreau, Phase Formation and Transformation in Alumina/YSZ Nanocomposite Coating Deposited by Suspension Plasma Spray Process, J. Therm. Spray Technol., 2010, 19(4), p 787-795

16. J. Oberste-Berghaus, S. Bouaricha, J.-G. Legoux, and C. Moreau, Injection Conditions and In-Flight Particle States in Suspension Plasma Spraying of Alumina and Zirconia Nano-ceramics, Thermal Spray 2005: Thermal Spray Connects: Explore Its Surfacing Potential!, May 2-4. E. Lugscheider Ed., DVS-German Welding Society, Basel, 2005, p 512-518

17. F. Tarasi, M. Medraj, A. Dolatabadi, J. Oberste-Berghaus, and C. Moreau, Amorphous and Crystalline Phase Formation During Suspension Plasma Spraying of the Alumina-Zirconia Composite, J. Eur. Ceram. Soc., 2011, 31(15), p 2903-2913

18. P. Fauchais, M. Vardelle, S. Goutier, and A. Vardelle, Key Challenges and Opportunities in Suspension and Solution Plasma Spraying, Plasma Chem. Plasma Process., 2014, 35(3), p 511-525

19. H.-B. Xiong and J.-Z. Lin, Nanoparticles Modeling in Axially Injection Suspension Plasma Spray of Zirconia and Alumina Ceramics, J. Therm. Spray Technol., 2009, 18(5), p 887

20. A. Ozturk and B.M. Cetegen, Modeling of Axially and Transversely Injected Precursor Droplets into a Plasma Environment, Int. J. Heat Mass Transf., 2005, 48(21), p 4367-4383

21. J. Schein, M. Richter, K.D. Landes, G. Forster, J. Zierhut, and M. Dzulko, Tomographic Investigation of Plasma Jets Produced by Multielectrode Plasma Torches, J. Therm. Spray Technol., 2008, 17(3), p 338-343
22. J. Richter and W. Lochte-Holtgreven, Plasma Diagnostics, North Holland, Amsterdam, 1968

23. B. Jähne, Digitale Bildverarbeitung, Vol 4 Springer, Berlin, 1997

24. K. Landes, G. Forster, J. Zierhut, M. Dzulko, and D. Hawley, Computer Tomography of Plasma Jets-Applied on a TRIPLEX II Torch, Thermal Spray 2004: Advances in Technology and Application, May 10-12, ASM International, Osaka, 2004, p 1129

25. M. Hugenschmidt, Lasermesstechnik, Springer, Berlin, 2007

26. K. Bobzin, T. Schläfer, I. Petkovic, K. Hartz-Behrend, K. Landes, G. Forster, S. Kirner, J.-L. Marqués, S. Zimmermann, J. Prehm, L. Xin, K. Möhwald, and F.-W. Bach, Homogenization of Coating Properties in Atmospheric Plasma Spraying-Results and Outlook of a DFG (German Research Foundation)-Funded Research Group, International Thermal Spray Conference, Sept 27-29, DVS Media, Hamburg, 2011

27. G. Mauer, R. Vaßen, D. Stöver, S. Kirner, J.-L. Marqués, S. Zimmermann, G. Forster, and J. Schein, Improving Powder Injection in Plasma Spraying by Optical Diagnostics of the Plasma and Particle Characterization, J. Therm. Spray Technol., 2011, 20(1-2), p 3-11

28. G. Mauer, J.-L. Marqués-López, R. Vaßen, and D. Stöver, Detection of Wear in One-Cathode Plasma Torch Electrodes and Its Impact on Velocity and Temperature of Injected Particles, $J$. Therm. Spray Technol., 2007, 16(5-6), p 933-939

29. P.-E. Danielsson and O. Seger, Generalized and Separable Sobel Operators, Machine Vision for Three-Dimensional Scenes. H. Freeman Ed., Academic Press, London, 1990, p 347-379

30. A. Kramida, Y. Ralchenko, J. Reader, and NIST ASD Team, NIST Atomic Spectra Database (version 5.8), Ed., National Institute of Standards and Technology, 2020

31. G. Scoles, Atomic and Molecular Beam Methods, Oxford University Press, Oxford, 1988

32. R.T. Jongma, T. Rasing, and G. Meijer, Two-dimensional imaging of metastable CO molecules, J. Chem. Phys., 1995, 102(5), p 1925-1933

Publisher's Note Springer Nature remains neutral with regard to jurisdictional claims in published maps and institutional affiliations. 